\title{
AN ANALISIS OF HEAT FLOWS IN THE COMBUSTION ENGINE OF A SHIP NON-CONVENTIONAL ENERGETIC SYSTEM
}

The paper describes a possibility of implementation of a non-conventional energetic system for ships. The described system is a source of heat at three levels, cool, refined electric energy and mechanical energy. Individual secondary energies are acquired by means of transformation of primary chemically bound energy in fuel. Primary energy is transformed by means of a combustion engine used as a driving unit of ships designed for transportation of passengers and goods. Mechanical energy can be used to drive a ship and its equipment. Exergy as a source of heat and cool for technological equipment of a ship. The implementation of a non-conventional system of a ship offers more possibilities for effective usage and increases energetic evaluation of the combustion engine in this means of transport. The paper analyses heat flows in the non-conventional cooling circuit of the combustion engine of a ship energetic system.

\section{Introduction}

Referring to [2] the non-conventional energetic system (NES) can be considered a source of electric energy, mechanical energy as well as heat energy. Heat energy can be obtained at three levels as:

- Highly potential heat in the form of water heated up to $100{ }^{\circ} \mathrm{C}$, which can be used by the ship for heating and technological operations,

- Medium potential heat, such as water heated up to $40 / 55^{\circ} \mathrm{C}$ to heat household water,

- Low potential heat of $7 / 16^{\circ} \mathrm{C}$ suitable for air conditioning.

To achieve optimal use of the energies it is necessary to define a convenient cooperation between the primary - main source of energy and equipment working with it. A suitable cooperation can lead to a more effective energetic assessment of the primary source, i.e. less consumption of primary energy needed to provide the required output energetic flows.

The non-conventional energetic system is based on flows of energy from the main or auxiliary ship combustion engine. It can ensure the supply of the energies for the ship energetic system. At present attention is focused on the investigation of cooperation of the combustion engine with the absorptive cooling equipment, Figure 1 . This cooperation is required by the need for application of technological and air conditioning operations aboard by means of the ship energetic center.

\section{An analysis of cooperation between the combustion engine and cooling equipment}

The absorptive cooling equipment can provide cooling for technological and air conditioning purposes in the energetic system of the ship. This can be provided by means of a suitable cooler.
To ensure the operation of such cooling equipment thermal energy featuring certain thermal states is needed. The suitable thermal states are provided by the cooling system of the combustion engine. We refer to the use of after-expansion energy accumulated in the engine coolant. This energy can be transported from the cooling system in two ways:

- To interconnect the combustion engine cooling system with the cooling equipment by means of hydraulic pipe and exchanger,

- To let the working medium from the absorptive cooling equipment flow directly to the engine block and in this way make full use of the temperature gradient of the cooling system at the defined flow. Losses in the hydraulic pipe and exchanger can thus be avoided. Alternative coolant must be used as a working medium in the engine cooling system.

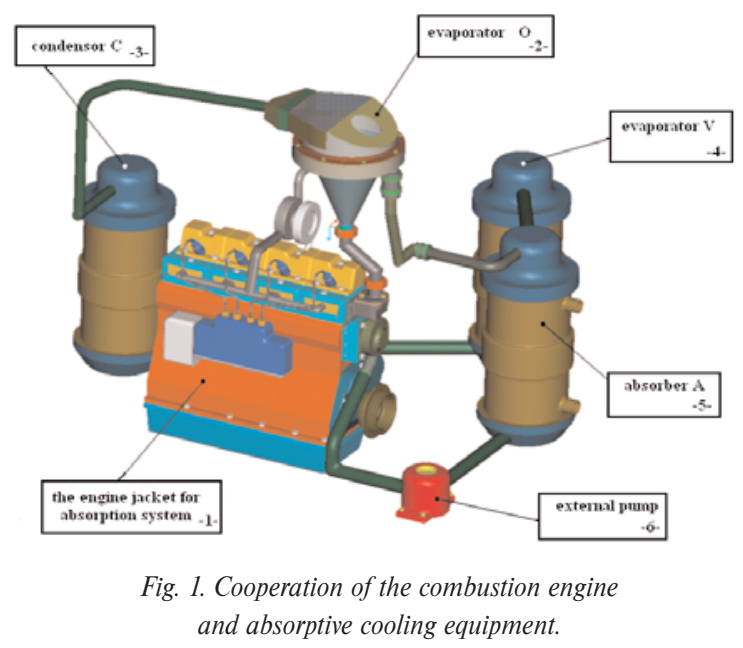

As the alternative coolant features other physical properties and the process of exergy usage in the cooling system is carried

\footnotetext{
* Hlavňa Vladimír, Sojčák Dušan

Faculty of Mechanical Engineering, University of Žilina, Univerzitná 1, 01026 Žilina, Slovakia,

E-mail: Vladimir.Hlavna@fstroj.utc.sk, Dusan.Sojcak@fstroj.utc.sk
} 
out under certain pressure and thermal conditions, it is expected that some changes in specific heat flows due to wet inserted cylinders will occur. Specific heat flows depend on mass flow of the coolant along individual cylinders, on velocity profile of flow in the engine block and on temperature gradient in the cooling system. The temperature profile on the cylinder liner corresponds to each heat flow.

To investigate heat flows and corresponding temperature profiles on the cylinder liner which result from the exchange of the coolant and from the change of pressure conditions in the engine cooling jacket it is necessary do design a model and define assumptions. For the purpose of the analysis we chose a diesel four cylinder engine having revolutions of $1500 \mathrm{~min}^{-1}$. Figure 2. shows a real cooling space which was transformed to a calculation model Figs. 3. and 4

\section{A mathematical model for flow analysis}

We start from the mathematical model for turbulent flow of the type "renormalized groups - RNG $k-\varepsilon$ - turbulent model". The renormalization procedure applied into turbulence lies in a gradual elimination of little whirls, while equations of motion are transformed (Navier - Stokes equations) so that turbulent viscosity, forces and nonlinear members are transformed. If we suppose that these whirls are related to dissipation $\varepsilon$, then the turbulent viscosity $\mu_{t}$ is dependent on the size of turbulent whirls and the RNG method constructs this viscosity by means of iterative elimination of narrow bands of wave numbers. The following equation is used for iterative process,

$$
\frac{d \mu_{e f f}}{d l}=\frac{A_{i} \varepsilon l^{3}}{\mu(l)^{2}} .
$$

The RNG model derived by a statistical method, averaged, is formally of the same form as the classical $k-\varepsilon$ model. The equation for transfer of motion is in the form:

$$
\begin{aligned}
& \frac{\partial}{\partial t}\left(\rho \bar{u}_{i}\right)+\frac{\partial}{\partial x_{j}}\left(\rho \bar{u}_{i} \bar{u}_{j}\right)=\frac{\partial}{\partial x_{j}}\left[\mu_{e f f}\left(\frac{\partial \bar{u}_{i}}{\partial x_{j}}+\frac{\partial \bar{u}_{j}}{\partial x_{i}}\right)-\right. \\
& \left.-\left(\frac{2}{3} \mu_{e f f} \frac{\partial \bar{u}_{i}}{\partial x_{i}}\right)\right]-\frac{\partial \bar{p}}{\partial x_{i}}+\rho g_{i}+F_{i},
\end{aligned}
$$

and, subsequently, transport equations are used:

$$
\begin{aligned}
& \frac{\partial}{\partial t}\left(\rho_{k}\right)+\frac{\partial}{\partial x_{j}}\left(\rho \pi_{j} k\right)=\frac{\partial}{\partial x_{j}}\left(\alpha_{k} \mu_{\text {eff }} \frac{\partial k}{\partial x_{j}}\right)+\mu_{t} S^{2}-\rho \varepsilon \\
& \frac{\partial}{\partial t}(\rho \varepsilon)+\frac{\partial}{\partial x_{j}}\left(\rho \mu_{j} \varepsilon\right)=\frac{\partial}{\partial x_{j}}\left(\alpha_{\varepsilon} \mu_{\text {eff }} \frac{\partial \varepsilon}{\partial x_{j}}\right)+ \\
& +C_{1 \varepsilon} \frac{\varepsilon}{k} \mu_{t} S^{2}-C_{2 \varepsilon} \rho \frac{\varepsilon^{2}}{k}-R
\end{aligned}
$$

For more details see [4].

\section{Accepted assumptions.}

The solution of heat spreading by means of conduction, convection, radiation in the combustion engine and in the cooling system is a highly complicated issue. The mathematical model including a complex state of heat spreading and other phenomena at passing from part of the combustion chamber to the space of the cooling system through all the elements is very complicated. This complication characterizes the defining of equation and geometric model and, consequently, calculation network. It is, therefore, necessary to accept more assumptions, which bring to the calculation itself simplifications and, thus, inaccuracy.

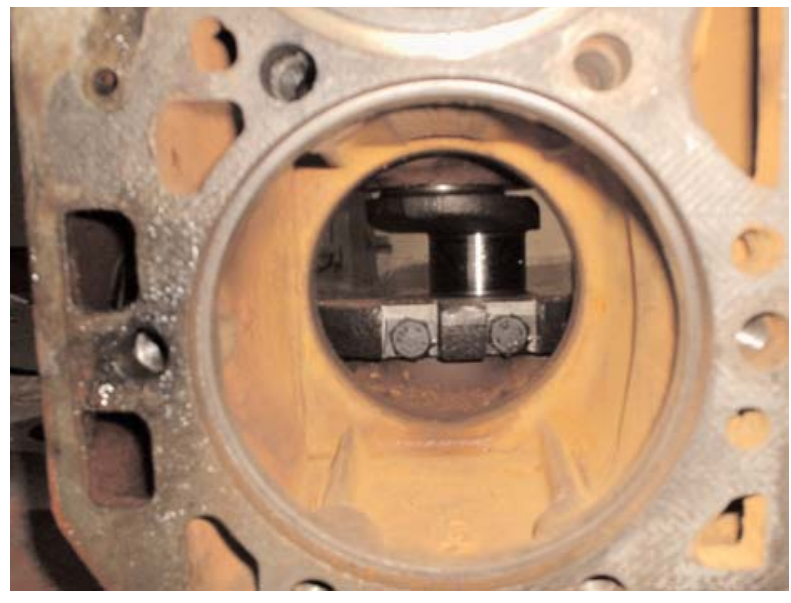

Fig. 2. Shape of the cooling space.

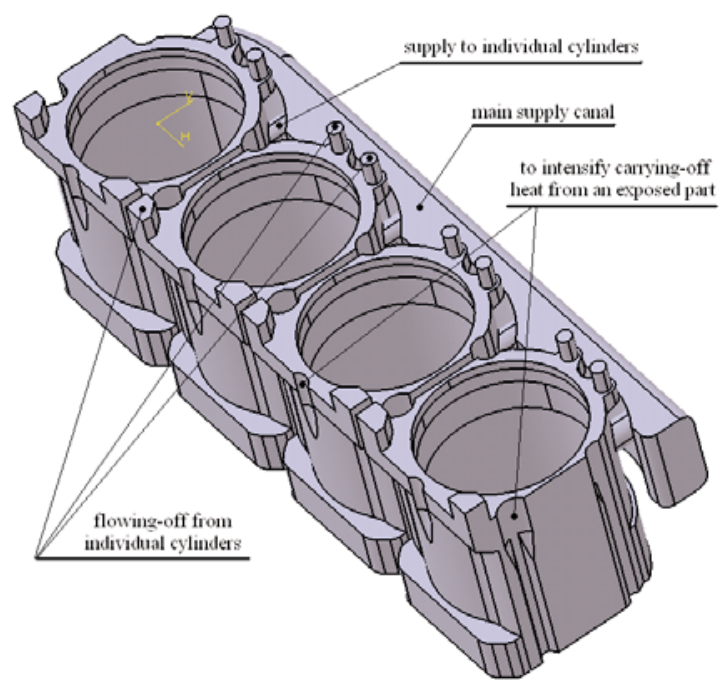

Fig. 3. Model of the cooling space.

Assumptions:

- Volume of liquid is considered only in the engine block, i. e. without the cylinder head,

- Influent field caused by the pump is not considered,

- The most serious assumption relates to combustion process. The model does not include the influence of combustion process. This influence can be observed only in the change of heat flows 


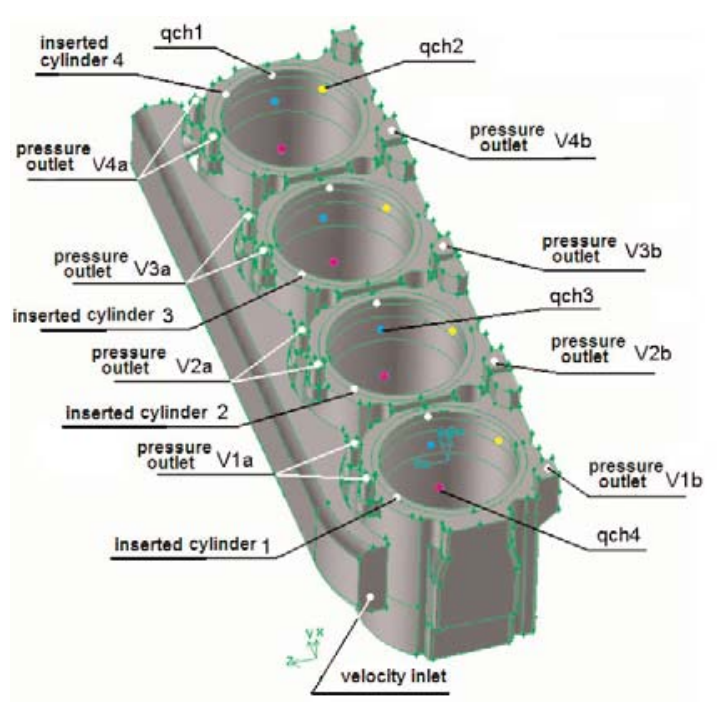

Fig. 4. Model of cooling space with defined places for calculation

through the cylinder liner at the calibration of the model for outside heat balance. Heat flows are caused by temperatures pertaining to the surfaces $q c h_{1}, q c h_{2}, q c h_{3}, q c h_{4}$. Here the assumption is accepted that the equal quantity of fuel from which equal quantity of heat is released be supplied into each cylinder. In this way heat flow through the cylinder liners occurs.

- An equally defined temperature profile on each cylinder liner from the side of combustion space is assumed.

\section{Physical properties of alternative coolant:}

Heat flows and temperature profiles acquired by calculation for water are considered referential. They serve for consequent comparison with heat flows and temperature profiles of an alternative coolant. The physical properties of the alternative coolant are shown in the graphs in Figs. 5 and 6. They are necessary for calculation.

Defined values of boundary conditions:

The value of boundary condition for pressure output is measured in the pump discharge, Fig. 7. The values of pressure for

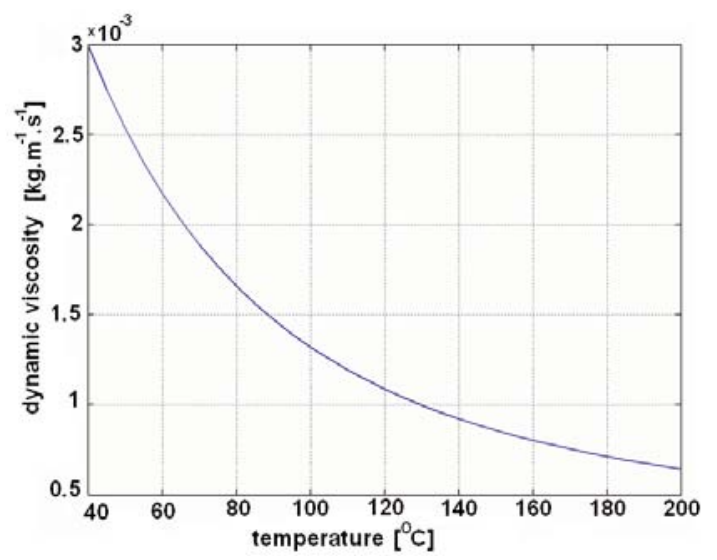

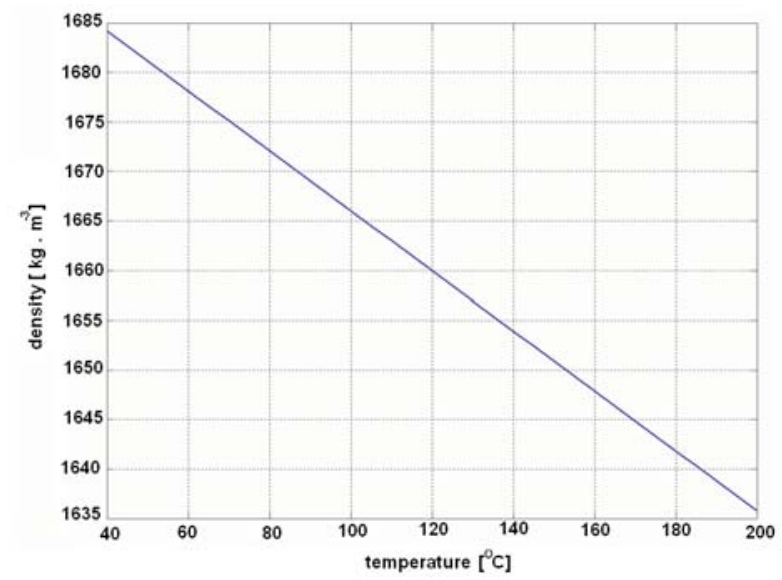

Fig. 6. Influence of change in temperature on density of alternative coolant

both (water and alternative coolant) liquids were measured in the input channel of the SM block and then applied to the boundary conditions of the pressure outlet type.

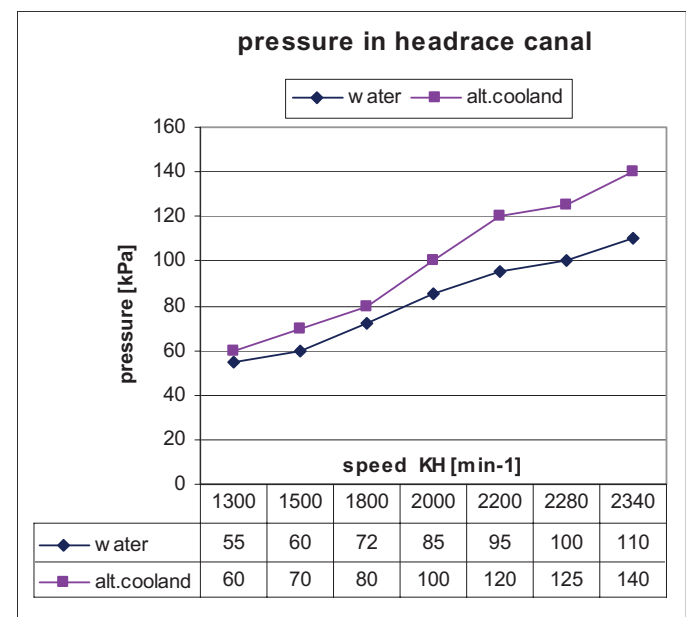

Fig. 7. Characteristic of the coolant pump

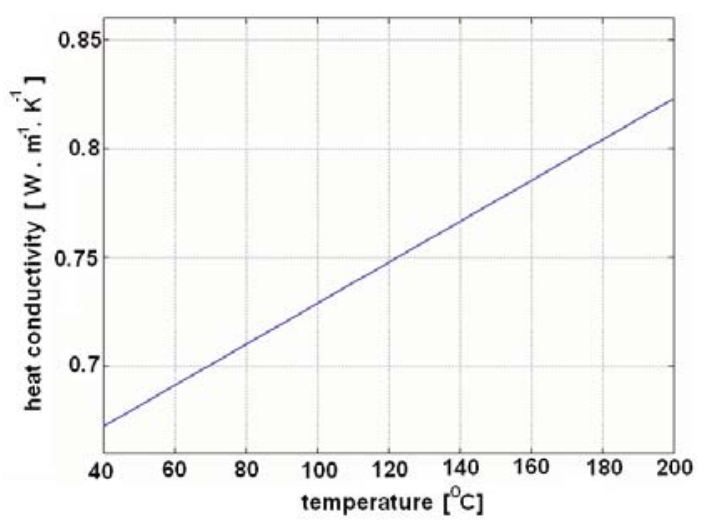

Fig.5. Influence of change in temperature on heat conductivity and dynamic viscosity of alternative coolant 
For velocity input - mass flow of fluid through the block is defined and consequently the following values are calculated:

- water $=1.01 \mathrm{~kg} \cdot \mathrm{s}^{-1}$

at temperature of $357.44 \mathrm{~K}, v=0.567 \mathrm{~m} . \mathrm{s}^{-1}$,

- alternative coolant $=1.88 \mathrm{~kg} \cdot \mathrm{s}^{-1}$

at temperature of $352.24 \mathrm{~K}, v=0.611 \mathrm{~m} . \mathrm{s}^{-1}$.

To bring about heat flows - temperatures on qch1, qch2, qch3, qch4 are applied so that the average temperature leaving the block will be equal to the one experimentally measured.

\section{The results achieved}

Suitability of the alternative coolant under heat, thermal, flow and pressure conditions is defined by means of velocity profile in the engine block, mass flow along individual cylinders, heat flows from the wet liners and by means of thermal profiles o the wet side of the inserted cylinders - see Figs. 8. - 13.

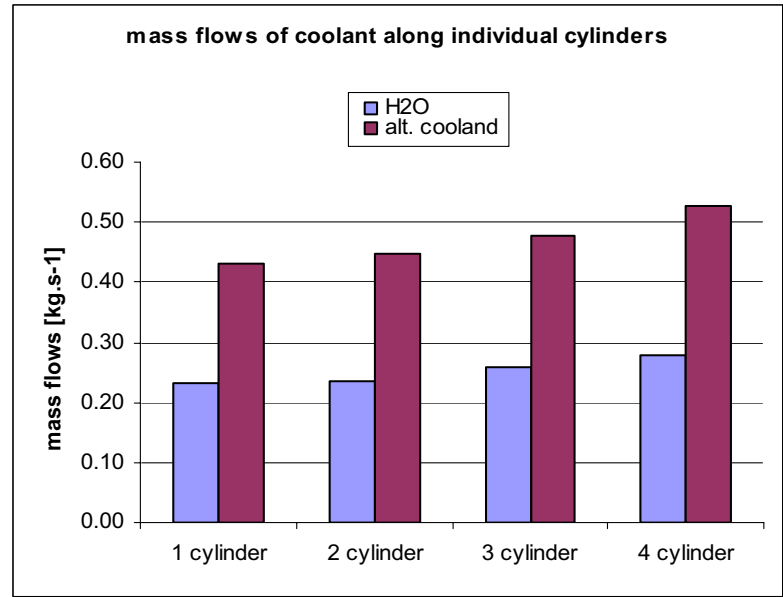

Fig. 8. Mass flows of coolant along individual cylinders

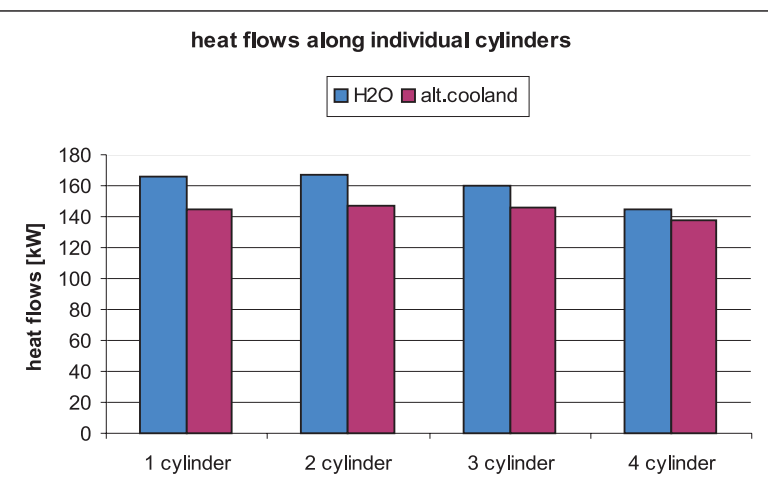

Fig. 9. Heat flows along individual cylinders

The above defined heat flows from the inserted cylinders correspond to the defined mass flows and velocity profiles. Though, temperature profiles on the wet wall of the inserted cylinder cor-

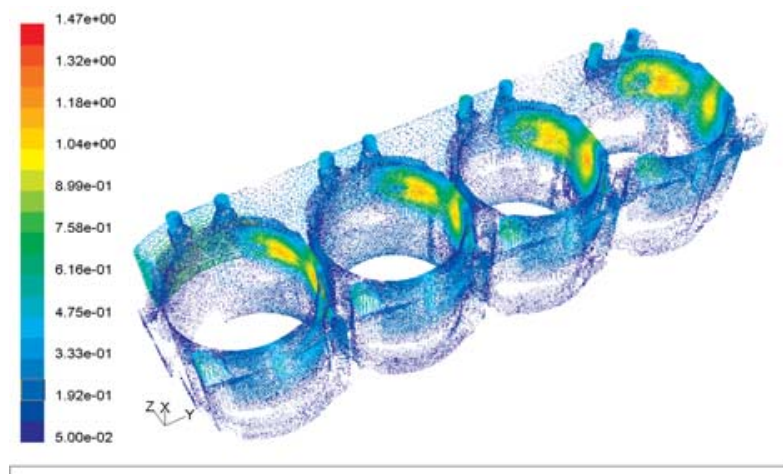

Velocity Vectors Colored By Velocity Magnitude (m/s)

Fig. 10. Velocity field of coolant $\mathrm{H}_{2} \mathrm{O}$ in the ICE block.

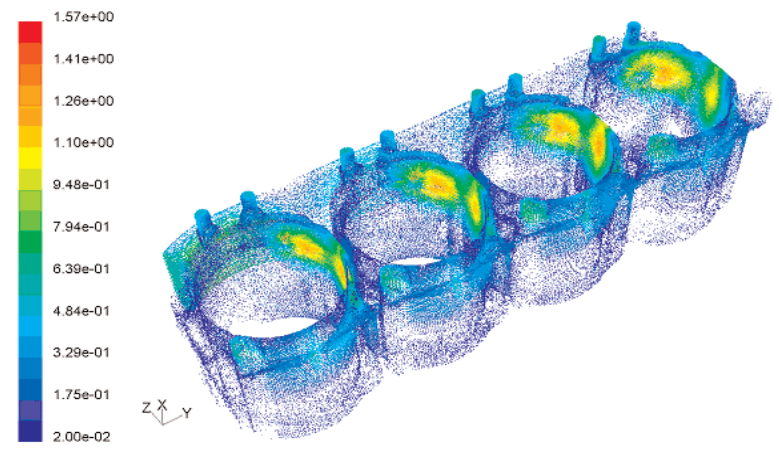

Fig. 11. Velocity field of alternative coolant in the ICE block.

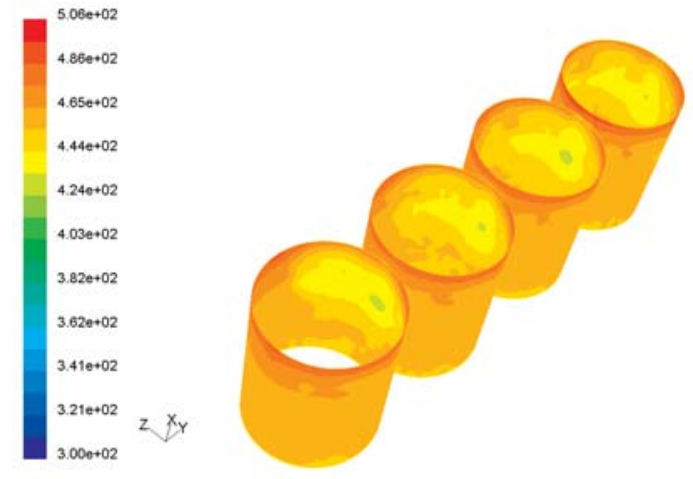

Cortours of Static Temperature $(k)$

Fig. 12. Temperature profile on the wet wall of the inserted cylinder for alternative coolant - thermal state at $1500 \mathrm{~min}^{-1}$.

respond to the heat flows. They characterize the cooling influence of individual coolants.

\section{Conclusion}

From the measured and calculated parameters we can assume that the alternative coolant brings about favorable values. 


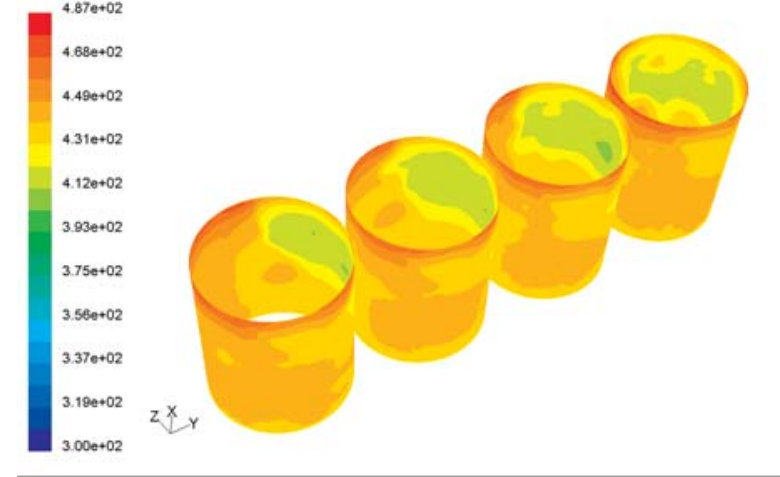

Cortours of Static Temperature (k)

Fig. 13. Temperature profile on the wet wall of the inserted cylinder for $\mathrm{H}_{2} \mathrm{O}$ - thermal state at $1500 \mathrm{~min}^{-1}$.

The values of the velocity field for both liquids do not exceed the recommended interval of maximum values of velocities defined by the interval 1-2 $\mathrm{m} \cdot \mathrm{s}^{-1}$. After the change of the cooling medium, the maximum velocities increased.
With regard to the higher density of the alternative coolant there is an increase in mass flows along individual cylinders.

Due to the change of the cooling medium (other physical properties) there was a decrease in the heat flows from individual liners. Though, their values remain within the interval of the recommended values, which is defined by the range of 110 to 190 $\mathrm{kW} \cdot \mathrm{m}^{-2}$ for a category of engines of which one engine was used for the experiment

From the acquired temperature profiles we can assume that after the change of the coolant there is a more uniform distribution of temperatures along the circumference and also alongside the cylinders.

The model defined in this way is able to model pressure and thermal states of the combustion engine block in dependence on flow conditions. These states result directly from the conditions of cooperation of the combustion engine with the absorptive cooling equipment.

\section{References}

[1] HLAVŇA, V., HUDÁK, A.: Some problems of ICE cooling systems, Konstrukcja, badania, eksploatacja, technologia pojazdow samochodowych i silnikow spalinowych, PAN Krakow, Zeszyt Nr. 26-27, 2003

[2] HLAVŇA, V, SOJČÁK, D.: Non-conventional energetic system for ships, Czasopismo techniczne z. 6 - M/2004, ISSN 0011-4561

[3] PIROCH, P.: Efektívnejšie využitie energie paliva v nekonvenčnom spalovacom motore, (in Slovak) Písomná práca k dizertačnej skúške, ŽU v Žiline, 2002

[4] SOJČÁK, D.: Spalovací motor s nekonvenčným chladiacim okruhom, (in Slovak), Písomná práca k dizertačnej skúške, ŽU v Žiline, 2003

[5] KONDEPUD, D.: Modern thermodynamics, John Wiley and Sons, 1998

[6] ȘENCAN, A., YAKUT, A., DIKMEN, E.: New model for determining the thermodynamic properties of libr-h2o solution, G.U. Journal of Science 17(1):101-110 - 2004, ISSN 1303-9709

The contribution was created within the framework of the project Nr. APVT - 20 - 010302, which is supported by the Agency for Support of Science and Technology of the Slovak Republic. 